\title{
Interdisciplinaridade e estatística nos dados de escravos sepultados em Porto Alegre (1850-1885)
}

\author{
Interdisciplinarity and statistics in the data of slaves buried at Porto Alegre (1850 to \\ 1885)
}

\author{
Leila Inês Pagliarini de Mello ${ }^{1}$ \\ Andréia Dalcin ${ }^{2}$ \\ Luciana Neves Nunes ${ }^{3}$
}

\begin{abstract}
Resumo
Este artigo apresenta resultados de uma pesquisa de um mestrado profissional no campo da Educação Estatística feita com estudantes do $7^{\circ}$ ano em uma escola privada de Canoas-RS. A questão A busca pela compreensão de dados demográficos dos escravos sepultados no cemitério da Santa Casa de Porto Alegre, no século XIX, pode contribuir no aprendizado de Estatística? serviu para um projeto interdisciplinar de Matemática, História e Ciências. Com uma amostra aleatória de 1559 registros de óbitos dos escravos constantes no livro "Africanos na Santa Casa de Porto Alegre: Óbitos dos escravos sepultados no cemitério da Santa Casa (1850 a 1885)", a turma fez gráficos e tabelas. Através de pré e pós testes se avaliou que houve avanços no aprendizado de conceitos estatísticos. Conceitos estatísticos foram mobilizados nas atividades e o olhar interdisciplinar favoreceu o processo de produção e análise dos dados, bem como fomentou o debate sobre a escravidão negra em Porto Alegre no século XIX.
\end{abstract}

Palavras-chave: Educação Estatística; Letramento Estatístico; Modelagem Matemática; Interdisciplinaridade; Ensino Fundamental.

\begin{abstract}
This paper presents results of a research of a professional master in the field of Statistical Education done with 7 th grade students in a private school in Canoas-RS. The question "Can the search for understanding demographic data of slaves buried in the cemetery of the Santa Casa de Porto Alegre, in the XIX Century, contribute to the learning of statistics?" served for an interdisciplinary project in Mathematics, History and Science. With a random sample of 1559 slave death records from the book "Africanos na Santa Casa de Porto Alegre: Óbitos dos escravos sepultados no cemitério da Santa Casa (1850 a 1885)" the class produced charts and tables. Through pretest and posttest it was evaluated that there were advances in the learning of statistical concepts. The statistical concepts were mobilized in the activities and the interdisciplinary look favored the
\end{abstract}

Submetido em: 25/09/2019 - Aceito em: 12/02/2020 - Publicado em: 14/04/2020

${ }^{1}$ Mestra em Ensino de Matemática pela Universidade Federal do Rio Grande do Sul; Professora da Rede Estadual de Ensino do Rio Grande do Sul, Brasil. Email: by.leila@gmail.com

${ }^{2}$ Doutora em Educação, área de Educação Matemática pela Universidade Estadual de Campinas; Professora do Departamento de Ensino e Currículo da Faculdade de Educação e do Programa de Pós-Graduação em Ensino de Matemática da Universidade Federal do Rio Grande do Sul, Brasil. Email: deiadalcin@ gmail.com

${ }^{3}$ Doutora em Epidemiologia pela Universidade Federal do Rio Grande do Sul; Professora do Departamento de Estatística do Instituto de Matemática e Estatística e do Programa de Pós-Graduação em Ensino de Matemática da Universidade Federal do Rio Grande do Sul, Brasil. Email: lununes@mat.ufrgs.br 
DOI: $10.20396 /$ zet.v28i0.8656749

process of data production and analysis, as well as assisted in the debate about black slavery in Porto Alegre in the XIX Century.

Keywords: Statistical Education; Statistical Literacy; Mathematical Modeling; Interdisciplinarity; Elementary School.

\section{Introdução}

A inserção da Educação Estatística na disciplina de Matemática é algo que vem ganhando espaço nas discussões, tanto na academia como nas escolas. A Educação Estatística oportuniza a compreensão de dados de determinados fenômenos e as inferências sobre eles, de modo a ser possível estabelecer conexões entre a Matemática e outras áreas de conhecimento, favorecendo o trabalho interdisciplinar. À vista disso, se faz necessário, ainda na Educação Básica, proporcionarem-se atividades que favoreçam o aprendizado de conceitos estatísticos e a interpretação de resultados obtidos com a Estatística Descritiva.

Neste contexto, entendemos ser necessária a construção do letramento estatístico, que, segundo Lopes (2010, p.2), "requer o desenvolvimento do pensamento estatístico, o qual permite que a pessoa seja capaz de utilizar ideias estatísticas e atribuir um significado à informação estatística". O letramento estatístico possibilita um posicionamento adequado do cidadão diante das mais variadas informações presentes na sociedade, e no apoio à construção de conhecimentos em outras áreas.

Os autores Akanime e Yamamoto (2009) definem a Estatística como a ciência que estuda as técnicas necessárias para coletar, organizar, apresentar, analisar e interpretar dados, a fim de extrair informações a respeito de uma população. Os Parâmetros Curriculares Nacionais (PCN) (MEC, 1998) englobam esses diversos tópicos sob o título Tratamento da Informação. Recentemente o texto da Base Nacional Comum Curricular (BNCC) (MEC, 2017) reforça a necessidade de uma Educação Estatística, entendida como algo mais amplo do que o ensino de conteúdos e conceitos da Estatística e aponta que os alunos ao final do Ensino Fundamental saibam planejar e construir relatórios de pesquisas, realizem e interpretem estatísticas descritivas que potencializam discussões sobre aspectos socioculturais, ambientais, enfim sobre fenômenos que afetam a vida.

A pesquisa, que aqui apresentamos, que resultou na dissertação de mestrado profissional intitulada "O aprendizado de conceitos de estatística através de um estudo sobre os óbitos dos escravos do Rio Grande do Sul no séc. XIX: uma experiência interdisciplinar", buscou problematizar o ensino da Educação Estatística e elencou como questão norteadora: $A$ busca pela compreensão de dados demográficos dos escravos sepultados no cemitério da Santa Casa de Porto Alegre, no século XIX, pode contribuir no aprendizado de Estatística?

Para o desenvolvimento da pesquisa propôs-se um cenário para investigação em sala de aula com estudantes do sétimo ano em uma escola privada do município de Canoas-RS. Segundo Lopes e Carvalho (2009), a problematização de um tema pode ser a semente que dará suporte a um trabalho de investigação, em que pode se propor aos estudantes a formulação de questões e a construção de explicações. Este cenário para investigação envolve 
o professor e sua turma, mas os/as estudantes são os principais responsáveis pelo processo investigativo.

Neste cenário, foi construído um projeto interdisciplinar, que contou com a participação, além da pesquisadora, que era a professora de Matemática da turma, dos professores de Ciências e História da escola. A sequência de atividades didáticas elaborada visava propor situações que criassem a possibilidade de alunos e alunas exercitarem a análise estatística de dados a partir dos registros de óbitos dos escravos sepultados no Cemitério Santa Casa de Porto Alegre, partindo-se de uma amostra aleatória da população. O desenvolvimento da capacidade de se estabelecer relações entre variáveis só acontece se o estudante conseguir se apropriar de conceitos e ideias estatísticas, tais como distribuição, medidas de posição, incerteza, amostra e população. Entende-se que se aprende estatística envolvendo-se com ela. Além disso, ao deparar-se com dados e informações reais, no processo de análise, poderiam emergir discussões sobre nosso passado de escravidão, estando a estatística como mobilizadora de debates sobre os valores e direitos humanos.

\section{Modelagem Matemática e Interdisciplinaridade: alguns princípios norteadores}

A Estatística nos auxilia a compreender diferentes fenômenos, dentre os quais os referentes às condições de vida, à preservação do meio ambiente e à promoção dos direitos humanos, que emergem cada vez mais na sociedade, e que requerem um olhar interdisciplinar. Lopes e Carvalho (2009) defendem que a Educação Estatística, nos anos finais do ensino fundamental, aconteça através da problematização, em que os alunos e alunas buscam, organizam e interpretam as informações. Neste exercício de organização e interpretação, vão emergindo discussões que potencializam uma leitura de mundo mais crítica e complexa.

Uma das possibilidades de se trabalhar a Educação Estatística nas aulas de matemática é por meio da modelagem matemática. Para Barbosa (2004, p.4), “a Modelagem é um ambiente de aprendizagem no qual os alunos são convidados a problematizar e investigar, por meio da matemática, situações com referência na realidade". Com base nesse mesmo autor, acreditamos que:

[...] O ambiente de modelagem está associado à problematização e investigação. o primeiro refere-se ao ato de perguntas e/ou problemas enquanto que o segundo, à busca, seleção, organização e manipulação de informações e reflexão sobre elas. ambas atividades não são separadas, mas articuladas no processo de envolvimento dos alunos para abordar a atividade proposta. nela, pode-se levantar questões e realizar investigações que atingem o âmbito do conhecimento reflexivo. (Barbosa, 2004, p. 75)

Entendemos que um ambiente investigativo e reflexivo, em uma prática que utiliza Modelagem Matemática na sala de aula, proporciona aos estudantes uma preparação para utilizar a matemática em diferentes contextos, além da compreensão do papel sociocultural que tem a matemática. 
DOI: $10.20396 /$ zet.v28i0.8656749

Segundo Barbosa (2001), os casos de Modelagem podem ser classificados em três formas diferentes, como está apresentado no Quadro 1.

Quadro 1- Classificação dos casos de modelagem de Barbosa (2001).

\begin{tabular}{|l|l|}
\hline Caso 1 & $\begin{array}{l}\text { O professor apresenta a descrição de uma situação-problema, com as informações } \\
\text { necessárias à sua resolução e o problema formulado, cabendo aos alunos o processo de } \\
\text { resolução. }\end{array}$ \\
\hline Caso 2 & $\begin{array}{l}\text { O professor traz para a sala um problema de outra área da realidade, cabendo aos alunos } \\
\text { a coleta das informações necessárias à sua resolução. }\end{array}$ \\
\hline Caso 3 & $\begin{array}{l}\text { A partir de temas não-matemáticos, os alunos formulam e resolvem problemas. Eles } \\
\text { também são responsáveis pela coleta de informações e simplificação das situações- } \\
\text { problema. }\end{array}$ \\
\hline
\end{tabular}

Em todos os casos, criam-se oportunidades para a realização de discussões nas aulas de Matemática com o objetivo de proporcionar reflexões sobre a realidade dos/das estudantes. Tais reflexões podem ser alicerçadas, mediadas ou mesmo representadas por números, tabelas e gráficos, de modo que a Educação Estatística esteja presente e integrada ao processo de modelação, favorecendo um trabalho interdisciplinar.

Lopes e Carvalho (2009) apontam a importância de promover atividades Interdisciplinares, em que os alunos e alunas em alguns momentos resolvem exercícios de um conteúdo exposto e, em outros, pesquisem e investiguem informações e dados. Buscou-se, na elaboração das atividades propostas para esta pesquisa, utilizar tal ideia, em consonância com o Caso 2, de Barbosa (2001), em que a professora-pesquisadora propôs um tema de pesquisa e, nas demais fases, ocorreu um trabalho conjunto entre docentes e discentes, no qual diferentes questionamentos foram elaborados e debatidos.

A ideia de interdisciplinaridade também está presente nos PCN (MEC, 1998) como forma de desenvolver a integração dos conteúdos de uma disciplina escolar com outras áreas de conhecimento, o que contribui para o aprendizado do aluno.

Segundo Fazenda (2011), “[...] a interdisciplinaridade é entendida como uma mudança de atitude na forma de conceber, compreender e entender o conhecimento, uma troca em que todos saem ganhando, uma vez que há uma mudança de atitude por parte dos envolvidos". Em síntese, a interdisciplinaridade almeja a construção de um conhecimento globalizante. Lodovici e Silveira (2011) afirmam que:

O recurso à interdisciplinaridade se impõe, portanto, pela necessidade de um método de análise do mundo, considerando as finalidades sociais desse conhecimento. As disciplinas, isoladamente, não podem responder de forma adequada a problemáticas extremamente complexas. Há necessidade de buscar sínteses conceituais que possibilitem o enfrentamento da investigação nas fronteiras das disciplinas. (Lodovici e Silveira, 2011, p.296) 
Para que a interdisciplinaridade se materialize é preciso romper com a visão fragmentada da realidade. Fazenda (2011) ressalta que a "interdisciplinaridade na educação vai além do desenvolvimento de novos saberes, pois favorece novas formas de aproximação da realidade, social e novas leituras das dimensões socioculturais das comunidades humanas" (Fazenda, 2011, p.22).

Neste contexto, de acordo com Lopes (2010),

\begin{abstract}
A Estatística, com os seus conceitos e métodos para coletar, organizar e analisar informações diversas tem-se revelado um poderoso aliado neste desafio que é transformar a informação bruta em dados que permitem ler e compreender uma realidade. Talvez por isso, se tenha tornado uma presença constante no cotidiano de qualquer pessoa, fazendo com que haja um amplo consenso em torno da ideia segundo a qual a literacia estatística deva ser uma prioridade da sociedade moderna, ou seja, de uma cidadania com responsabilidade social. (Lopes, 2010, p.1)
\end{abstract}

Percebe-se, portanto, a importância da Estatística para a formação do educando, como conhecimento que o instrumentaliza para a tomada de decisões em condições de incerteza, relacionando conteúdos escolares com fatos da vida social.

Como dizem Campos et al (2013), quando o olhar do professor se volta para questões de ensino e aprendizagem em que é proporcionado um ambiente no qual se destacam a investigação e a reflexão como elementos fundamentais no processo de construção do conhecimento, podem ser trabalhados os princípios da Educação Estatística. Portanto, projetos de modelagem matemática, na linha do aprender fazendo (learning by doing) podem ser desenvolvidos.

\title{
Procedimentos metodológicos e prática pedagógica - Descrição e Resultados
}

Para a produção de dados para a pesquisa foi realizado um projeto de ensino interdisciplinar. A opção pela temática de se trabalhar com os dados sobre os escravos sepultados no Cemitério Santa Casa de Porto Alegre foi resultado do diálogo com o professor de História da escola, que mencionou que o Arquivo Histórico da Santa Casa de Porto Alegre possui um acervo que poderia ser uma boa fonte de dados, dentre estes, os óbitos de pessoas livres e escravizadas no século XIX. Tal ideia despertou o interesse também da professora de Ciências, devido ao possível estudo das doenças associadas às mortes.

Inicialmente, os professores de Matemática, História e Ciências se articularam para a construção de um projeto de ensino interdisciplinar e decidiram, por questões logísticas, que os/as estudantes do sétimo ano da escola seriam convidados a fazer parte do projeto. Este projeto tornou-se o objeto de estudo da pesquisa de mestrado em questão. Os professores consideraram que para a realização do projeto seria melhor incluir estudantes voluntários porque a execução da pesquisa seria realizada no contraturno e o "aceitar o convite", segundo Barbosa (2001), é essencial para que ocorra o ambiente de envolvimento dos alunos na investigação matemática. 
DOI: $10.20396 /$ zet.v28i0.8656749

Participaram da pesquisa nove estudantes voluntários com a anuência dos pais que assinaram o Termo de Consentimento. $\mathrm{O}$ desenvolvimento da prática pedagógica ocorreu no primeiro semestre de 2016.

Trazemos os procedimentos e resultados específicos desenvolvidos na área da Matemática, cujo objetivo era estabelecer um ambiente para um trabalho com modelagem matemática em sala de aula que se enquadre no Caso 2, definido por Barbosa (2001).

A fim de reunir ferramentas sobre o conhecimento prévio e a consolidação dos conceitos estatísticos abordados, foram utilizados questionários pré-teste e pós-teste. O préteste continha sete questões, sendo três delas de múltipla escolha, formadas por conteúdos de estatística básica. As duas primeiras questões eram abertas e identificavam se os/as participantes tinham conhecimento sobre o conceito de população e amostra. A terceira e quarta questões eram de leitura e interpretação de gráficos; a quinta, sexta e sétima questões sobre moda, média e mediana, respectivamente. Para avaliar a consolidação do aprendizado, foi realizado o pós-teste contendo as mesmas questões do pré-teste, três meses após o término da prática pedagógica. Nesta avaliação foram comparadas as percentagens de acertos no préteste e no pós-teste, a partir da correção feita pela professora-pesquisadora.

Foram realizados 12 encontros semanais com a turma, totalizando 26 horas trabalhadas em conjunto. Nesses encontros foram usados os computadores da biblioteca da escola e a internet. Para completar todas as tarefas propostas, os/as participantes também tiveram horas de trabalho sem a presença dos professores, geralmente em suas casas, individualmente ou mesmo em grupo. Através da utilização de recursos tecnológicos, o grupo trabalhou de diferentes formas, incluindo momentos à distância com o uso de ferramentas de apoio do Google, a exemplo do Google Forms, Google Drive, Google Docs e discussão em um grupo de WhatsApp criado pelos alunos.

Após a aplicação do pré-teste no primeiro encontro, os conceitos de população e amostra foram abordados através de uma apresentação de slides. Neste encontro começou o manuseio, pelos participantes, do livro "Africanos na Santa Casa de Porto Alegre: Óbitos dos escravos sepultados no cemitério da Santa Casa (1850-1885)" uma obra de Flores (2007) que tinha sido proposto como objeto de estudo pelo professor de história. A partir desse contato com o livro, a turma tomou conhecimento que a população a ser estudada era dos escravos que foram sepultados no Cemitério da Santa Casa, entre os anos de 1850 e 1885. A Figura 1 exibe a capa do livro utilizado e um exemplo de como os dados dos registros dos óbitos dos escravos constam no livro. 


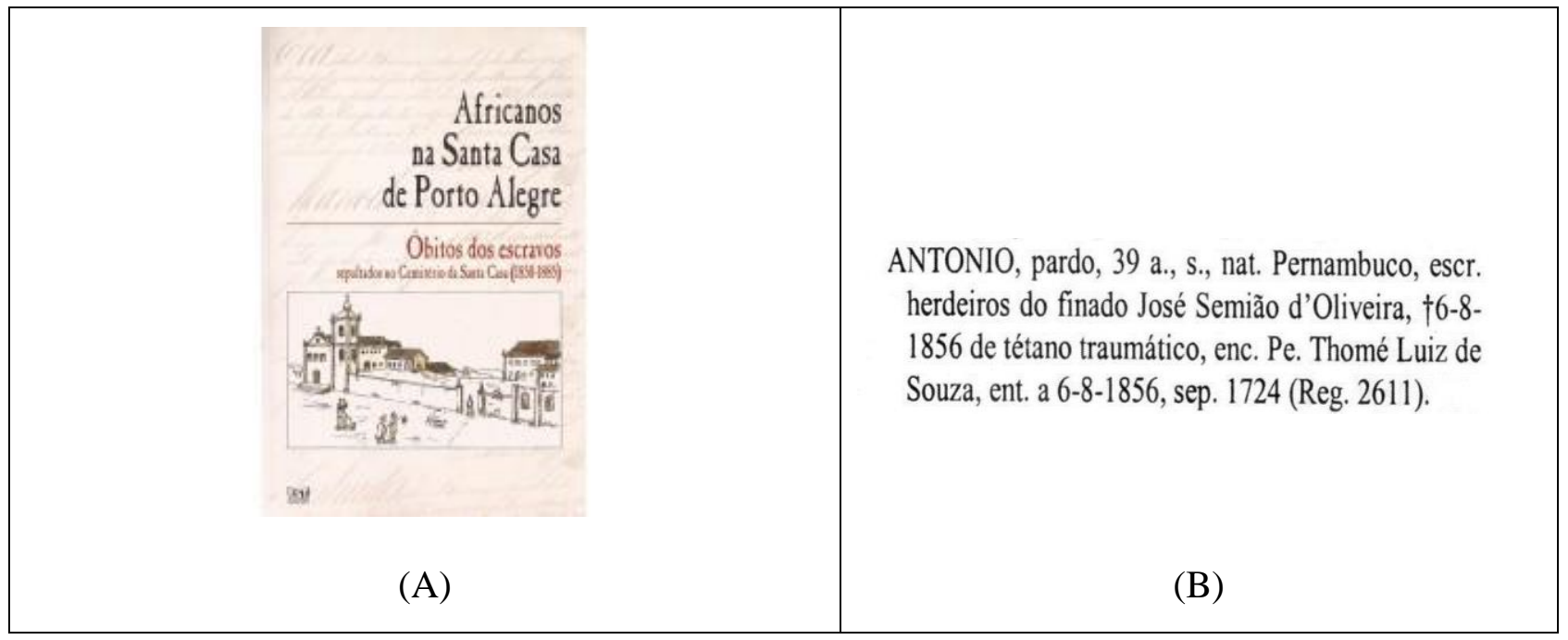

Figura 1 - (A) Capa do livro de Flores (2007); (B) Exemplo de um registro de óbito como consta no livro.

Fonte: Livro “Africanos na Santa Casa de Porto Alegre: Óbitos dos escravos sepultados no cemitério da Santa Casa (1850-1885)"

O livro de Flores (2007) tem os dados dos registros de óbitos de aproximadamente 7000 escravos, que faleceram no período de 1850 a 1885. A partir da leitura do livro e de uma discussão, os/as estudantes entenderam que o tamanho da população tratada era muito grande, então resolveram selecionar aleatoriamente uma amostra. A partir de uma discussão conduzida pela professora, ficou resolvido que a amostra seria composta por $25 \%$ dos dados de forma sistemática, ou seja, de maneira que selecionasse registros contidos no livro do começo ao fim. A decisão sobre o tamanho da amostra partiu dos participantes que observaram que o livro traz os registros em ordem cronológica e estão dispostos em colunas, sendo duas colunas por página. Intuitivamente, a turma decidiu usar a amostragem sistemática, pois ficou decidido que seria inserido no banco de dados uma coluna a cada duas páginas. A rapidez da turma em estabelecer o tamanho da amostra e a forma de selecioná-la superou a expectativa. Os os/as estudantes demonstraram o entendimento de que a amostra deve ser representativa e aleatória.

Na sequência, foi apresentado para a turma o recurso computacional Google Forms como uma ferramenta para criação de banco de dados, e após terem entendido como utilizálo, foi gerado um banco com os dados de uma amostra aleatória de 1559 casos de óbitos. O banco de dados que seria utilizado para a construção de gráficos e tabelas foi finalizado no quarto encontro, sendo que nesse período algumas dificuldades sobre o uso dos recursos tecnológicos foram superadas pela turma, por vezes com o auxílio dos professores, mas também de forma autônoma. A interdisciplinaridade estava presente já na coleta dos dados, como por exemplo, na digitação da causa mortis dos escravos, a cada doença desconhecida eles pesquisavam na internet o significado e imagens associadas a ela, indicando a necessidade de interação com a área de Ciências.

Nos quinto e sexto encontros o professor de História abordou assuntos relativos à trajetória e vida dos escravos e a importância da boa qualidade dos registros. Esse momento 
DOI: $10.20396 /$ zet.v28i0.8656749

foi importante, pois algumas definições foram esclarecidas para a conclusão da construção do banco de dados. Por exemplo, os/as estudantes tiraram algumas dúvidas sobre a nacionalidade dos escravos, que era uma das variáveis que constava nos registros. $\mathrm{O}$ professor esclareceu que era chamado de "crioulo" quem tinha nascido no Brasil, e "africano", aquele que tinha como nacionalidade os países da África. O professor também comentou que as crianças, até os 7 anos, na época, eram consideradas como "inocentes" e por volta de 15 anos como adultos. Neste encontro os/as estudantes escolheram a idade de 60 anos para definir o idoso, sendo adulto entre e de 15 a 59 anos. Além disso, também foram abordados elementos como as funções que exerciam e as doenças dessa população. $\mathrm{O}$ esclarecimento dessas ideias era importante para a análise estatística, no que se refere ao entendimento da demografia histórica. Neste momento a interdisciplinaridade com a História se mostrou fundamental para o andamento do estudo da turma.

Para as doenças descritas na causa mortis, o professor de História sugeriu que fossem classificadas com base no trabalho de Lycurgo Santos Filho, autor da obra História geral da medicina brasileira (1947). Explicou para a turma que o estudo da causa mortis é um dos indicativos das condições de vida no âmbito do período estudado, sendo uma janela pela qual podemos verificar suas possíveis agruras, marcadas ou não por suas condições de alimentação, vestimentas, ofícios e castigos.

Nesta etapa também foram abordados os conteúdos de moda, média e mediana. A professora-pesquisadora fez o uso de uma apresentação de slides e disponibilizou a apresentação no ambiente virtual Google Docs com o objetivo de levar os/as estudantes a conhecer o ambiente e utilizá-lo para fixar os conceitos estudados e avaliar o entendimento deles. O grupo mostrou muito interesse pelo novo ambiente, principalmente pela possibilidade de uso simultâneo, e o utilizaram exaustivamente. Sobre os conceitos estatísticos abordados, a maior dificuldade surgiu com o conceito e cálculo de mediana. A Figura 2 ilustra o uso do ambiente virtual Google Docs. 
DOI: $10.20396 /$ zet.v28i0.8656749

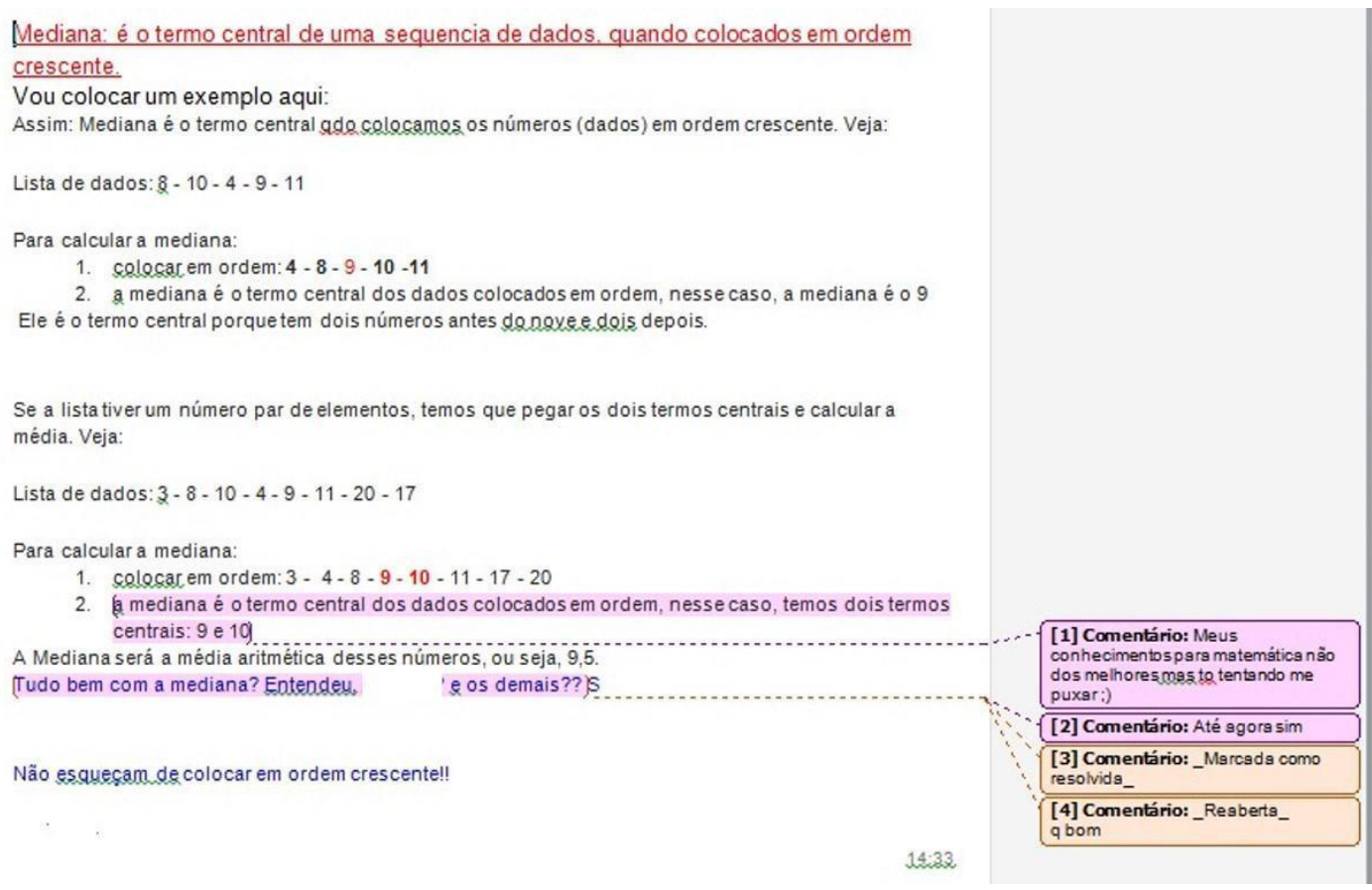

Figura 2 - Ilustração do uso do Google Docs.

Fonte: Acervo das autoras

Para os/as estudantes compreenderem a origem dos dados com os quais estavam trabalhando, o sétimo encontro foi uma visita ao Centro Histórico-Cultural Santa Casa. A turma foi acompanhada dos professores de Matemática e sua orientadora de mestrado e do professor de História. Inicialmente, assistiram a uma palestra educativa feita por uma museóloga sobre a história do Complexo Hospitalar Santa Casa de Misericórdia, com ênfase ao seu caráter de assistência, ao Cemitério da Santa Casa e seu Arquivo Histórico. Nesta ocasião, os estudantes tiveram a oportunidade de manusear o livro original de Registro de Óbitos do Cemitério da Santa Casa que deu origem a obra de Flores (2007). A Figura 3A ilustra esse momento da pesquisa.

Foi muito importante para os/as estudantes o manuseio do documento que deu origem à obra estudada em sala de aula. A partir dessa visita tiveram conhecimento do fato de que, na época desses registros, os óbitos dos escravos eram dispostos separadamente das pessoas livres. Assim como os sepultamentos eram feitos em locais separados no cemitério. Os estudantes perceberam quão importante foi o trabalho dos historiadores que construíram tais registros. A cada verbete lido, do livro original de óbitos dos escravos, lembravam-se da digitação de algo parecido. As letras, que são manuscritas, receberam uma atenção especial, pela forma que eram escritas, praticamente um desenho e de entendimento não muito fácil, conforme pode ser visto na Figura 3B. 


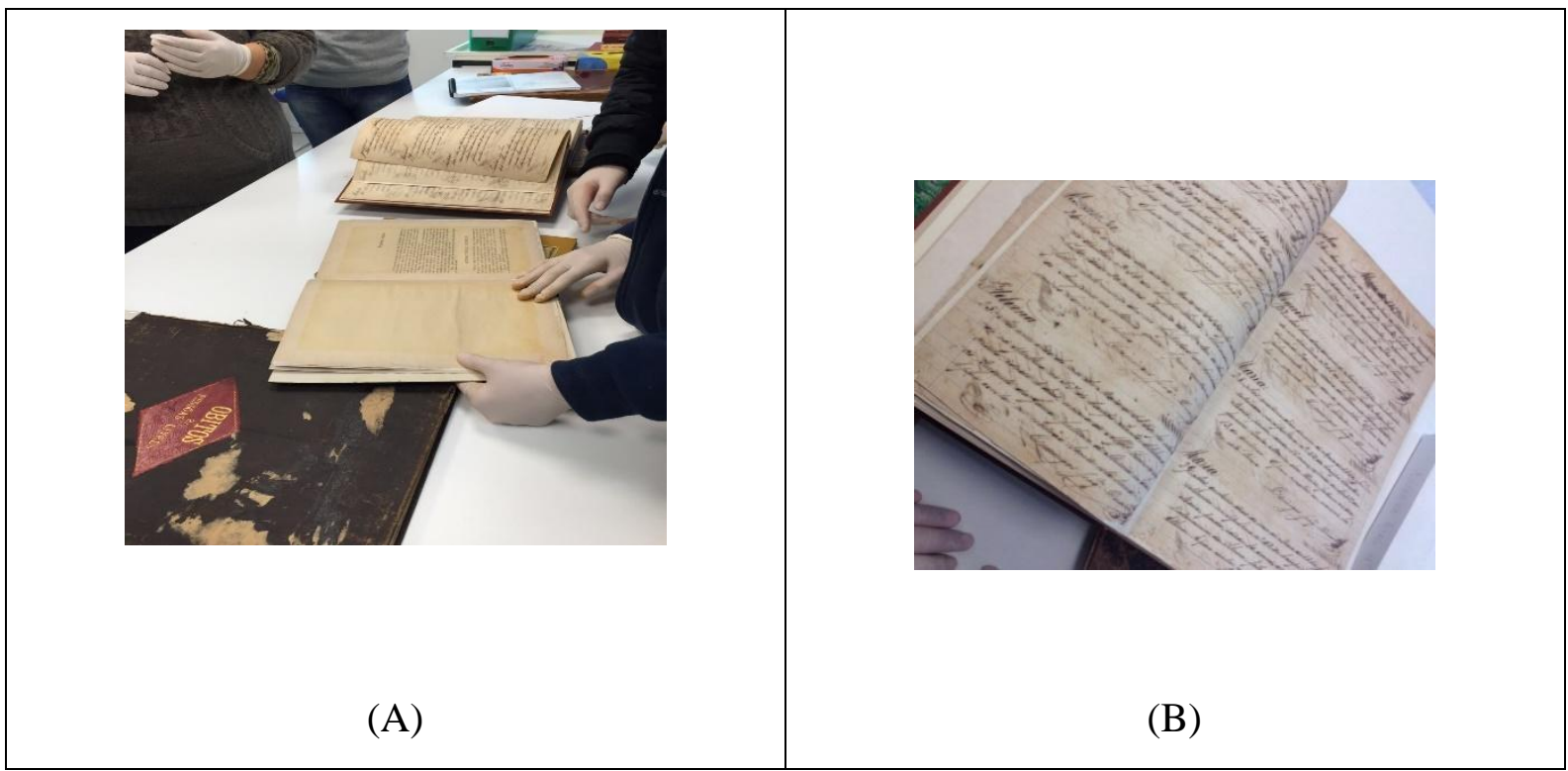

Figura 3 - (A) Estudantes manuseando o livro original de registro de óbitos dos escravos no Cemitério da Santa Casa; (B) Livro original de registro de óbitos, pertencente ao Arquivo Histórico da Santa Casa.

Fonte: Acervo das autoras

Nos encontros seguintes (do $8^{\circ}$ ao $10^{\circ}$ ), os/as estudantes realizaram um refinamento dos dados coletados, gerando as primeiras produções a partir das análises estatísticas. Neste processo foi utilizado como recurso computacional o software de planilha de dados Excel.

As Figuras 4 a 7 são gráficos produzidos pelos participantes durante as atividades e estão apresentados neste trabalho sem nenhuma modificação. Por isso, alguns problemas, como por exemplo a formatação da figura ou uso de letras minúsculas de forma inadequada, aparecem. Os títulos internos das figuras são de autoria dos estudantes e não sofreram quaisquer modificações.

Na Figura 4 é apresentado um gráfico de setores produzido pelos estudantes. A escolha por esse tipo de gráfico foi fundamentada na classificação da variável "nacionalidade" a ser representada, que era do tipo qualitativa. Considerando-se os resultados obtidos sobre a nacionalidade, de acordo com o que foi discutido com o professor de História, os/as estudantes observaram que $35 \%$ dos escravos eram africanos, $60 \%$ eram crioulos e $5 \%$ não tinham nacionalidade informada. Além do incentivo a apropriação do conceito estatístico de frequência relativa, numa discussão junto com o professor de História, tal resultado provocou o estudo sobre a reprodução endógena, cada vez mais incentivada a partir do ano de 1850, com a Lei Eusébio de Queiróz, que proibiu o tráfico de escravos para o Brasil. Ou seja, a partir de resultados estatísticos, se fomentou o estudo de leis e fatos históricos. Esse momento da pesquisa indicou o desenvolvimento do letramento estatístico dos estudantes, no que se refere à reflexão sobre os resultados estatísticos e atribui um significado a esses resultados. 
DOI: $10.20396 /$ zet.v28i0.8656749

\section{Nacionalidade dos escravos \\ Cemitério Santa Casa (1850-1885)}

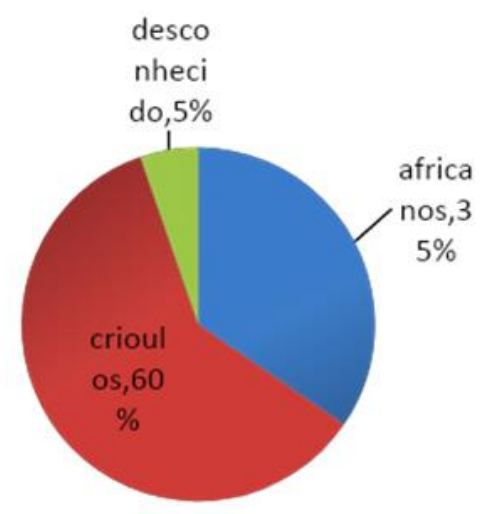

Figura 4 - Gráfico de setores para a variável "nacionalidade dos escravos" produzido pela turma.

Fonte: Acervo das autoras

A fim de se avaliar a relação entre as variáveis "sexo" e "idade", a turma decidiu por transformar a idade, que foi coletada em anos, em uma variável categórica. Para isso, consideraram a proposta feita pelo professor de História, e classificaram como "inocentes" os óbitos de pessoas com até 7 anos, "jovens" de 8 a 14 anos, "adultos" de 15 a 59 anos e "idosos" com 60 anos ou mais. Para ilustrar a relação entre essas variáveis, a turma optou por produzir um gráfico de colunas múltiplas, que é indicado para a representação visual do cruzamento de variáveis e está apresentado na Figura 5. Os resultados obtidos oportunizaram uma reflexão conjunta da turma envolvendo as disciplinas de Ciências e História. O gráfico mostrou existir um desequilíbrio entre o número de óbitos de homens e mulheres. No grupo dos inocentes, os estudantes observaram que havia uma equiparação entre a quantidade de óbitos de meninos e meninas. Mas, conforme a idade vai avançando evidenciou-se, nos dados analisados, mais óbitos de pessoas do sexo masculino, o que talvez possa ser explicado por existirem mais homens nesta população, em todas categorias de idade (jovens, adultos e idosos). Entretanto, a proporção de óbitos das mulheres nas categorias "jovens" (41\%) e "adultos" (42\%), foi mais alta quando comparada com a categoria "idosos" (28\%). A partir deste resultado pode-se explorar com a turma, na disciplina de Ciências, certas causas de morte, que se davam durante o parto ou alguns dias após o nascimento do bebê, como por exemplo através do estudo de doenças como o tétano e as formas precárias do parto, o que justificaria o registro no óbito as causas de morte como: "de parto", "ao nascer", "fora do tempo" e "mal dos sete dias". Novamente, foi possível trazer para a sala de aula reflexões de natureza estatística, como por exemplo, discutir sobre a qualidade dos dados que se tem disponível, na relação com conhecimentos históricos e biológicos, que possibilitaram analisar os resultados encontrados. 
DOI: $10.20396 /$ zet.v28i0.8656749

Sexo dos escravos

Cemitério Santa Casa (1850-1885)

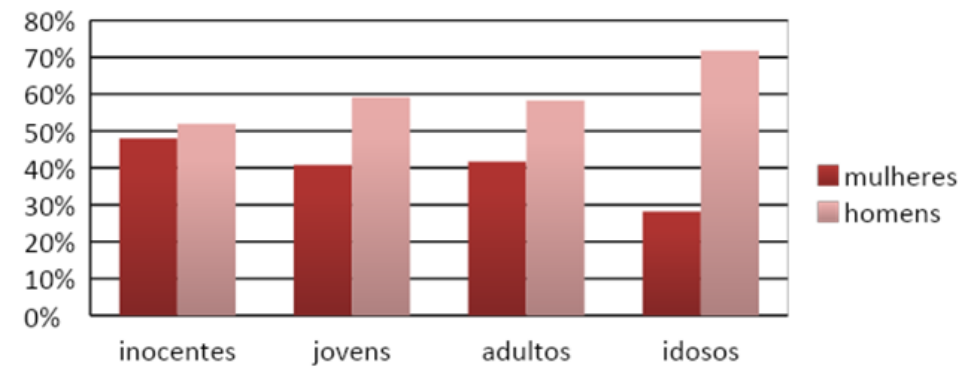

Figura 5 - Gráfico de colunas múltiplas produzido pela turma para representar a relação das variáveis "sexo" e "idade".

Fonte: Acervo das autoras.

A medida em que a análise exploratória de dados foi acontecendo, hipóteses sobre os dados iam sendo elaboradas. A partir da observação de alguns resultados, os/as estudantes suspeitaram que ao longo do tempo o comportamento do número de óbitos se modificou e que isso poderia estar relacionado com a idade com que as pessoas faleciam. Para investigar a incidência de falecimento de acordo com a idade, a partir de sugestão feita pela própria turma, a amostra foi reorganizada em dois grupos, de acordo com uma nova variável, a "faixa etária", categorizada em: inocentes (até 14 anos) e adultos (15 anos ou mais). Foi decidido mostrar as incidências de óbitos ano a ano através de um gráfico de linhas (ou gráfico de séries temporais), pois a ideia era investigar como a variável "número de óbitos/ano" se comportava.

Na Figura 6 é apresentado o gráfico produzido pela turma. Eles perceberam que existia um "pico" elevado de mortes no ano de 1855, e tal resultado foi facilmente explicado, tanto com elementos do campo da História como da Ciências, pois 1855 foi um ano de epidemia de cólera. Também por meio da análise do gráfico da Figura 6 os/as estudantes puderam observar que o número de óbitos, entre os escravos, diminui com o passar dos anos, especialmente entre os inocentes. Nas aulas da disciplina de História fez-se uso do gráfico para debater as questões sociais que poderiam justificar essa redução no número de óbitos dos escravos com o passar dos anos, e, em especial, o número de óbitos de inocentes depois de 1872 e, assim estabelecer correlação entre o comportamento da variável e a Lei do Ventre Livre (1871) que declarou libertos todos os filhos de escravos nascidos a partir dela, fazendo com que os inocentes falecidos passassem a ser registrados como pessoas livres. Ou seja, a partir dos resultados estatísticos, foi possível para o professor de História problematizar o fato de que apesar do gráfico aparentemente indicar que o número de óbitos das pessoas escravizadas estava diminuindo ao longo do tempo, isso não era verdade. O professor esclareceu que de fato o que mudou foi o documento em que eram registrados os óbitos, pois as pessoas mudaram seu status de escravos para livres. Este momento da pesquisa ilustra como a criticidade sobre resultados estatísticos pode ser trabalhada em sala de aula. Embora o gráfico que a turma tenha feito esteja correto estatisticamente, ele não explicita o que aconteceu historicamente, isto é, os negros e negras continuaram em condições precárias de 
DOI: $10.20396 /$ zet.v28i0.8656749

vida mesmo depois de livres e seguiram vindo a óbito por vários motivos.

Escravos sepultados

Cemitério Santa Casa (1850-1885)

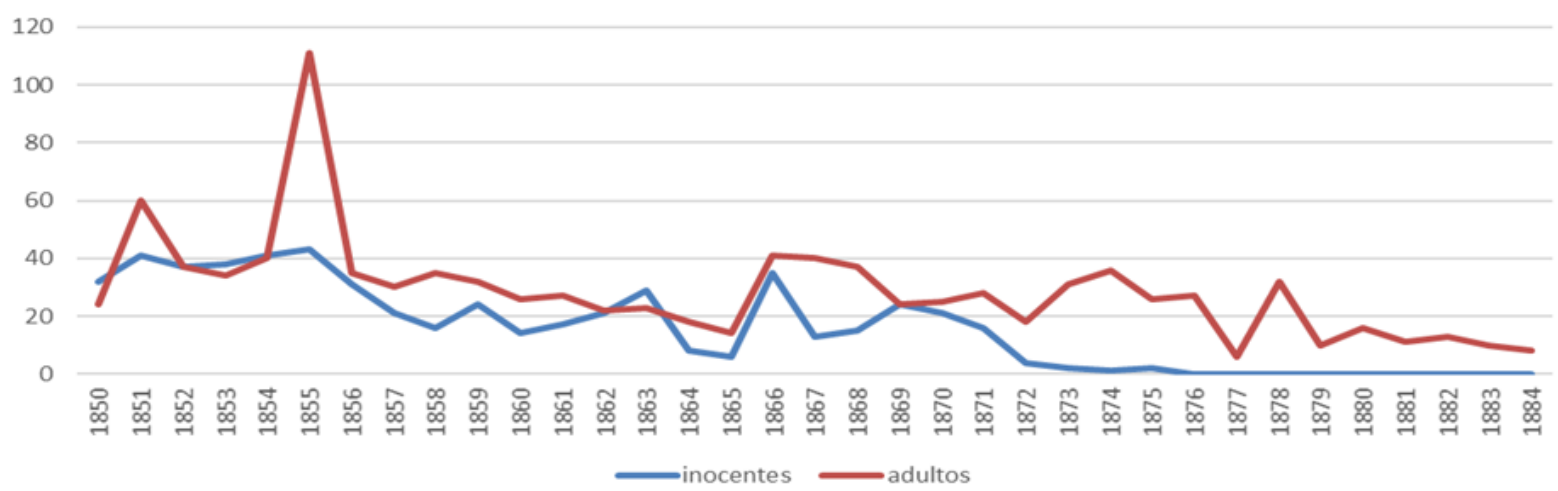

Figura 6 - Gráfico de séries temporais para representar o comportamento da variável "número de óbitos por ano" de acordo com a variável "faixa etária” produzido pela turma.

Fonte: Acervo das autoras.

O $11^{\circ}$ encontro foi destinado ao estudo das doenças que foram definidas como causa mortis. Com a participação e condução da discussão da professora de Ciências, os/as estudantes agruparam as doenças de acordo com a classificação do livro História geral da medicina brasileira (1947), que classifica as doenças da época estudada em 11 grupos. A ideia era identificar as doenças com maior incidência. Entretanto, para fim de organização dos dados, a professora de Ciências orientou os participantes a classificarem os motivos de causa mortis em quatro categorias, conforme o gráfico apresentado na Figura 7, produzido pela turma que optou por um gráfico de setores, devido a variável ser do tipo qualitativa.

\section{Doenças dos escravos - Causa mórtis Cemitério Santa Casa (1850-1885)}

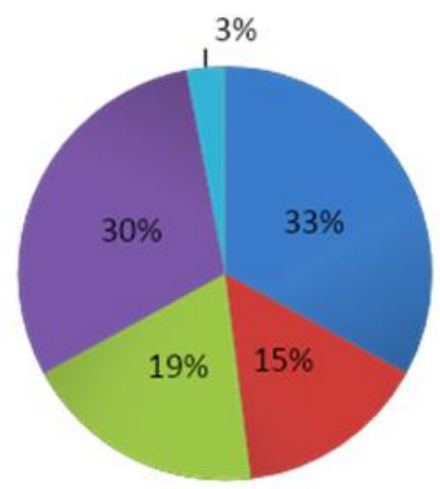

Doenças infecciosas e parasitárias

Doenças do Aparelho respiratório

- Doenças e sintomas mórbidos mal

definidos

Outras Doenças

Doenças desconhecidas

Figura 7 - Gráfico de setores produzido pela turma para representar a variável causa mortis.

Fonte: Acervo das autoras. 
Nos resultados observados da Figura 7, os/as estudantes concluíram que se destacaram as doenças infectocontagiosas e parasitárias que acometeram 33\% dos escravos e as doenças respiratórias foram responsáveis por $15 \%$ dos óbitos. Entretanto, $19 \%$ tinham como causa mortis "doenças desconhecidas ou mal definidas". A experiência vivenciada com a professora de Ciências nesse encontro foi relevante pois, além de ser discutida a forma de avaliar estatisticamente a variável causa mortis, foi possível realizar uma crítica sobre a qualidade das informações constantes sobre os óbitos descritos.

No $12^{\circ}$ e último encontro, os/as estudantes prepararam o banner para as apresentações na modalidade Pôster de alguns eventos. Os/as estudantes que participaram desse projeto tiveram a oportunidade de apresentar seu trabalho no Salão Científico da escola em julho/2016 e também em eventos externos educativos, tais como o I Workshop de Iniciação Científica Júnior da APECS-Brasil em Brasília - julho/2016, no Salão Jovem da UFRGS em outubro/2016 e no III Festival de Ciência em Porto, Portugal em outubro/2017. Em todos os eventos em que estiveram presentes foi apresentado um único banner da turma, que indicava os resultados da pesquisa. Nas apresentações, os/as estudantes se organizavam de modo que todos pudessem falar sobre algum aspecto da pesquisa. Em função das despesas financeiras, nem todos os estudantes estiveram presentes em todos os eventos.

\section{Análise do pré-teste e pós-teste}

Com o objetivo de avaliar o quanto cada estudante obteve de conhecimento sobre os conceitos estatísticos, foram aplicados um pré-teste e um pós-teste três meses após o final da prática pedagógica. A ideia de se aplicar o pós-teste depois de três meses da prática pedagógica é porque se julgou que este seria um tempo razoável para que os estudantes não tivessem as questões do pré-teste memorizadas. Constatou-se pela comparação dos resultados do pré-teste e pós-teste realizado, apresentados na Figura 8, que o conhecimento de Estatística do grupo de estudantes envolvidos na prática pedagógica aumentou, pois é possível se observar uma melhora no índice de acertos. $\mathrm{O}$ gráfico da Figura 8 mostra o percentual de acertos de cada uma das sete questões aplicadas nos dois momentos. 
DOI: $10.20396 /$ zet.v28i0.8656749

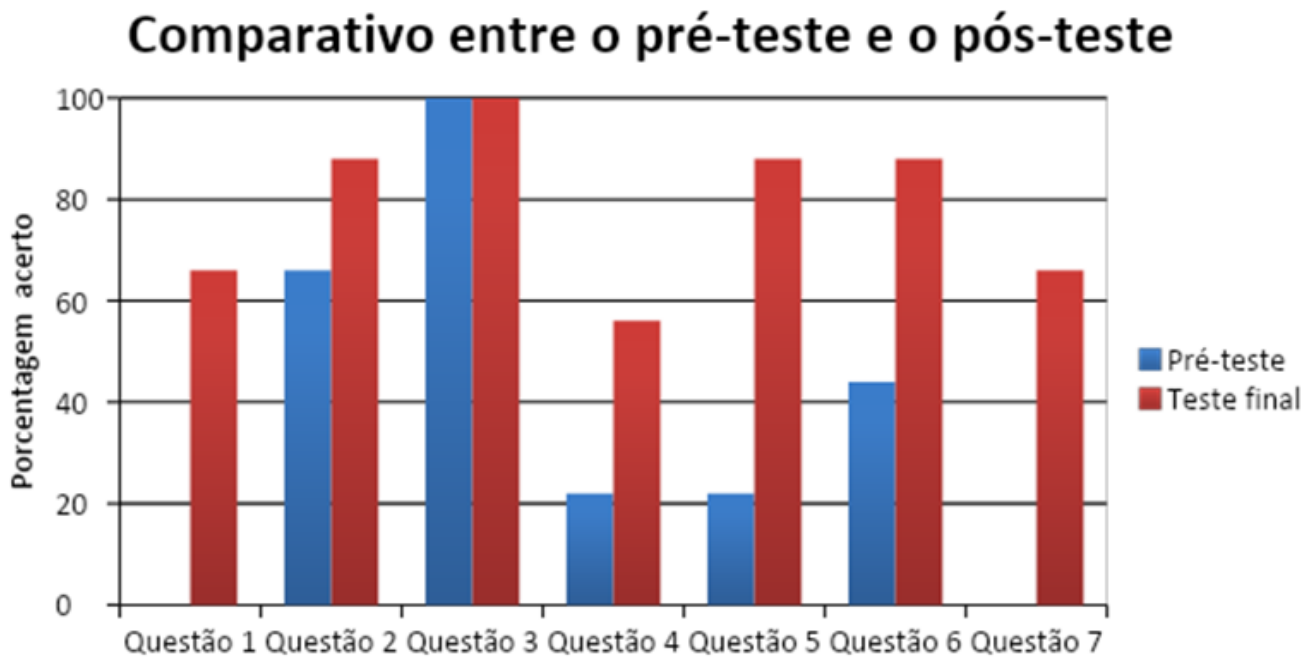

Figura 8 - Percentual de acertos em cada uma das sete questões do questionário aplicado no pré-teste e pósteste.

A primeira questão "O que significa população? Escreva uma frase usando a palavra população", deixou claro que o grupo de estudantes tinha o conhecimento de população em termos geográficos, ou seja, entendiam a população como "o total de habitantes de uma região ou país". Como todos erraram a resposta a esta questão no pré-teste, concluiu-se que não conheciam a definição de população em Estatística. No pós-teste, $66 \%$ do grupo acertou a questão, o que nos dá indícios de terem conseguido expandir o conceito para outros exemplos diferentes de população de número de pessoas de um local.

A questão 2 era "O que significa amostra? Escreva uma frase usando a palavra amostra.". No pré-teste foi possível se observar que os estudantes tinham alguma ideia sobre o conceito de amostra, pois $66 \%$ do grupo acertou a questão. Entretanto, cabe comentar que entre os que acertaram o conceito de amostra, 45\% dos respondentes usaram a palavra população nas suas definições, e em $95 \%$ das respostas certas apareceu a ideia de "parte de um todo". Percebe-se que a questão da representatividade não foi abordada pela maioria do grupo, aparecendo em apenas $22 \%$ das respostas. Para o pós-teste o percentual de acertos da questão subiu para $88 \%$. 
DOI: $10.20396 /$ zet.v28i0.8656749

Quadro 2- Questões 3 e 4 usadas no pré e pós testes

3) (OBMEP 2007) O número de consultas mensais realizadas em 2006 por um posto de saúde está representado no gráfico abaixo. Em quantos meses foram realizadas mais de 1200 consultas?

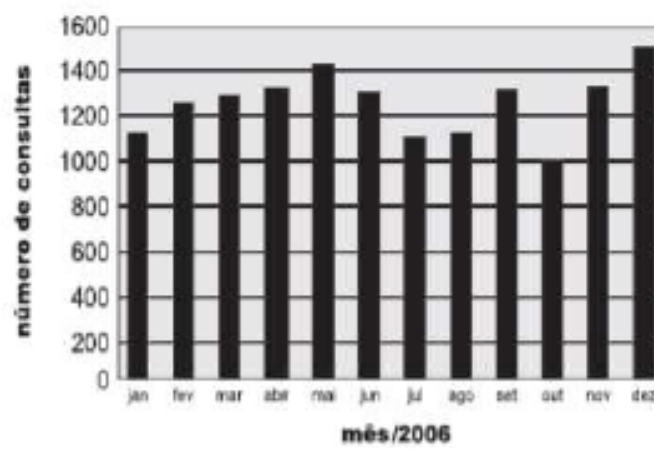

a) 5

b) 6

c) 7

d) 8

e) 9

4) (ENEM 2002) Em reportagem sobre crescimento da população brasileira, uma revista de divulgação científica publicou tabela com a participação relativa de grupos etários na população brasileira, no período de 1970 a 2050 (projeção), em três faixas de idade: abaixo de 15 anos; entre 15 e 65 anos; e acima de 65 anos.

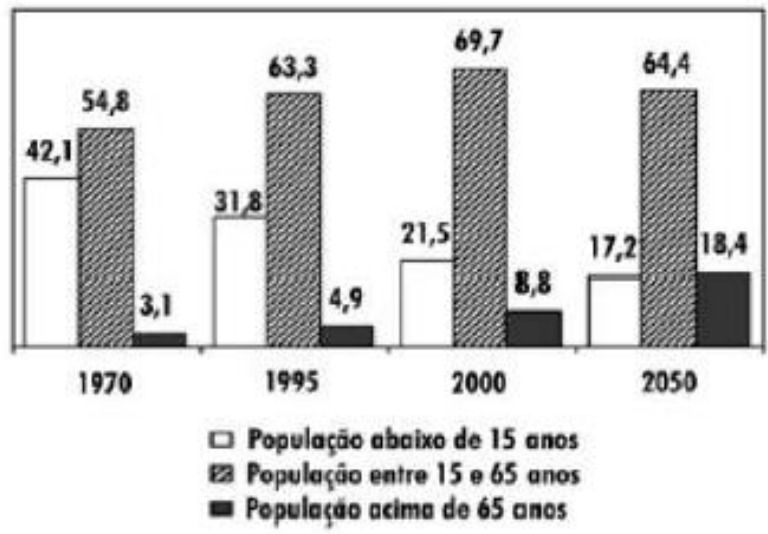

Admitindo-se que o título da reportagem se refira ao grupo etário cuja população cresceu sempre, ao longo do período registrado, um título adequado poderia ser:
a) "O Brasil de fraldas"
b) "Brasil: ainda um país de adolescentes"
c) "O Brasil chega à idade adulta"
d) "O Brasil troca a escola pela fábrica"
e) "O Brasil de cabelos brancos"

A terceira questão, apresentada no Quadro2, teve como objetivo principal identificar se os participantes conseguiam, a partir da análise das informações apresentadas em um gráfico tipo barras, interpretar e responder perguntas relacionadas a ele. Para avaliar essa habilidade, escolheu-se uma questão que fez parte da avaliação da Olimpíada Brasileira de 
Matemática das Escolas Públicas, em 2007. Todos acertaram essa questão, tanto no pré-teste como no pós-teste.

Uma questão de baixo índice de acerto no pré-teste foi a questão 4, que também tinha por objetivo avaliar a habilidade de interpretação de gráficos (ver Quadro 2). Foi utilizado uma questão do Exame Nacional do Ensino Médio (ENEM) de 2002, que envolvia um gráfico de colunas múltiplas. No pré-teste, $22 \%$ dos estudantes acertaram, contudo o grupo demonstrou uma melhora na interpretação da questão, pois $55 \%$ acertaram no pós-teste.

As questões 5, 6 e 7 avaliaram conceitos de moda, média e mediana, e o desempenho da turma foi baixo no pré-teste, sendo que os percentuais de acertos foram $22 \%, 44 \%$ e $0 \%$, respectivamente. Na questão 5 que era sobre a moda, " $O$ que significa moda em estatística? Escreva uma frase usando a palavra moda.", o grupo relacionou o conceito com a frequência mais alta, com exemplos pertinentes a moda em estatística. Todos os participantes desenvolveram corretamente o procedimento do cálculo da média aritmética na questão 6 (ver Quadro 3), entretanto houve erro na extração dos dados da tabela apresentada, o que gerou erro na soma dos dados. Ainda na última questão, que tratava da mediana, os/as estudantes mostraram total desconhecimento sobre esse conceito no pré-teste. Foi possível verificar que houve um aumento no percentual de acertos, quando avaliado o desempenho nessas questões no pós-teste em relação ao pré-teste. O percentual de acertos subiu para $88 \%$ nas questões 5 e 6. Na última questão do teste, a questão 7 (ver Quadro 3) que era sobre mediana, ninguém acertou a questão no pré-teste, o que demonstrou um desconhecimento do assunto. Evidenciou-se que não sabiam o que era mediana, pois ninguém escreveu sobre a mediana, mas comentaram sobre a variabilidade das idades, fugindo do tema ou referenciando-se a média das idades. Já no pós-teste, todos os responderam, demonstrando o entendimento sobre mediana como o termo central de uma lista de dados. Entretanto, $66 \%$ da turma acertou o valor da mediana. Os demais cometeram o mesmo erro que foi considerar como valor da mediana o valor central, mas sem levar em conta que a lista de dados deveria estar ordenada. 
DOI: $10.20396 /$ zet.v28i0.8656749

Quadro 3- Questões 6 e 7 usadas no pré e pós testes

6) (FUNCAB - 2013 - PM-ES) A tabela abaixo representa os dados dos balanços das operações do Batalhão de Polícia de Trânsito (BPTran) da Polícia Militar ES em três grandes feriados nacionais do ano de 2012.

\begin{tabular}{|c|c|c|c|}
\hline Feriados & $\begin{array}{l}\mathrm{N}^{0} \text { total de } \\
\text { acidentes }\end{array}$ & $\begin{array}{l}\mathrm{N}^{0} \text { total } \\
\text { de mortos }\end{array}$ & $\begin{array}{l}\mathrm{N}^{\mathrm{T}} \text { total } \\
\text { de feridos }\end{array}$ \\
\hline $\begin{array}{c}\text { Dia do } \\
\text { Trabalho }\end{array}$ & 220 & 2 & 78 \\
\hline $\begin{array}{c}\text { Dia de } \\
\text { Finados }\end{array}$ & 186 & 2 & 54 \\
\hline $\begin{array}{c}\text { Proclamaçăo } \\
\text { do Republica }\end{array}$ & 219 & 1 & 51 \\
\hline
\end{tabular}

(Fonite: <hitp:i/unww.pm.es.gov.bribptran/s)

O valor que melhor representa a média do número de feridos, de acordo com a tabela acima, é:
A) 57
B) 59
C) 61
D) 63
E) 65

7) Em uma escola, foram registradas as idades de um grupo de alunos do $9^{\circ}$ ano de acordo com o sexo. A partir dos valores obtidos, formaram-se as seguintes tabelas:

\begin{tabular}{|l|l|l|l|l|l|l|l|}
\hline Meninas & 15 & 13 & 14 & 16 & 14 & 15 & 15 \\
\hline
\end{tabular}

\begin{tabular}{|l|l|l|l|l|l|l|l|l|l|}
\hline Meninos & 14 & 16 & 14 & 15 & 15 & 13 & 15 & 14 & 14 \\
\hline
\end{tabular}

A mediana das idades das meninas e dos meninos é a mesma? Explique a sua resposta.

Cabe comentar que ao longo da prática, os conceitos de moda, média e mediana foram trabalhados, entretanto os resultados não foram explicitados neste artigo. Tiveram atividades propostas no Google Docs, como por exemplo responder um quiz que envolvia perguntas sobre esses conceitos. E, ao longo da análise estatística dos dados dos óbitos perguntas como: "Qual a moda de idade entre os óbitos de 1955? E a mediana?" ou "Calcule a média aritmética da idade dos escravos que faleceram devido a cólera", foram propostas.

\section{Considerações finais}

Ao longo da pesquisa, buscou-se alternativas para se trabalhar conceitos estatísticos no Ensino Fundamental. Procurou-se mostrar a importância da Educação Estatística, bem 
como a sua articulação em um estudo interdisciplinar, tendo a Estatística como ferramenta de comunicação entre as diferentes áreas do conhecimento.

Logo no primeiro momento, quando foi divulgada a proposta de estudo aos estudantes, pode-se observar uma aceitação do convite feito pela professora. Embora a resposta positiva ao aceite tenha sido pequena na turma, pois somente nove estudantes acolheram a proposta e esta aceitação, segundo Barbosa (2001), é essencial para que ocorra o ambiente de envolvimento dos estudantes na investigação matemática. O número pequeno de participantes pode ser uma limitação deste estudo, mas isso ocorreu por ter sido uma atividade desenvolvida no contraturno. Entretanto, cabe comentar que este mesmo fato favoreceu debates muito ricos e intensos dentro do grupo, em que todos participavam ativamente.

A abordagem pela Modelagem Matemática possibilitou aos estudantes a oportunidade de vivenciar aulas que favoreceram o envolvimento e a colaboração de todos os participantes, na realização de um trabalho investigativo que aproximou a Matemática escolar dos componentes de História e Ciências. Ao longo das atividades foi possível perceber a aplicabilidade de conceitos estatísticos a partir de um contexto interdisciplinar.

Na busca pela compreensão de dados demográficos dos escravos sepultados no cemitério da Santa Casa de Porto Alegre, no século XIX, os estudantes vivenciaram a seleção de uma amostra aleatória, a construção do banco de dados e a elaboração das distribuições de frequência e gráficos adequados, considerando as características das variáveis do estudo e, por fim, fizeram a análise dos resultados estatísticos produzidos, que sintetizavam os principais assuntos abordados pelas disciplinas de História e Ciências. A interdisciplinaridade e o embasamento da Modelagem Matemática oportunizaram que o aprendizado estatístico dos estudantes fosse desenvolvido e as discussões ocorridas ao longo de todo o período mostraram que esse tipo de ensino favoreceu o entendimento dos conceitos estatísticos abordados, como visto na comparação dos resultados do pré-teste e pós-teste. A busca pelo conhecimento da causa da morte dos escravos sepultados no cemitério da Santa Casa de Porto Alegre, no século XIX, oportunizou aos estudantes conhecerem as condições precárias que se encontravam os escravos no íntegro da população: viviam em lugares baixos, mal arejados, poucos espaçosos e aglomerados. Esta pesquisa permitiu que os professores das diferentes áreas trouxessem para a sala de aula questões sociais importantes como discriminação e racismo, muito presentes até os dias atuais, o que gerou alguns debates entre os/as estudantes, sendo possível perceber que ao longo da jornada na realização deste estudo, eles puderam desenvolver uma visão crítica a partir da análise dos dados. Essa criticidade apareceu nos trabalhos que foram apresentados nos diferentes eventos em que participaram.

Também merece destaque o uso de tecnologias, como o uso do Google Forms, de apresentação em slides, do Google Docs e o uso de planilhas eletrônicas, que ajudaram em todas as etapas da prática pedagógica, seja na criação do banco de dados, na exposição dos conteúdos, na construção de gráficos ou mesmo na elaboração dos relatórios e apresentações. 
Estudar conceitos estatísticos operando com dados históricos, em uma perspectiva interdisciplinar, evidenciou uma excelente oportunidade de uma experiência com Educação Estatística, ou seja, mais do que ensinar Estatística foi possível contribuir para a formação de uma consciência sobre o passado, necessária para a formação de cidadãos críticos que poderão usar o conhecimento adquirido para lutar no presente por um futuro melhor, com menos discriminação e preconceitos.

Por fim, evidenciamos com esta pesquisa que o estudo da Estatística com efeito, se tornou o elo entre disciplinas, impulsionando o trabalho interdisciplinar. Neste sentido, continuaremos a investigar em novas pesquisas o potencial da Estatística em práticas pedagógicas interdisciplinares.

\section{Referências}

Akanime, C. T., \& Yamamoto, R. K., (2009). Estudo Dirigido de Estatística Descritiva. $2^{\mathrm{a}}$ ed. São Paulo: Érica.

Barbosa, J. C. (2004). Modelagem matemática: O que é? Por que? Como?. Veritati, (4), p.7380.

Barbosa, J. C. (2001). Modelagem na Educação Matemática: Contribuições para o Debate Teórico. ANPED, 1 CD-ROM. Retirado em 15 de outubro, 2017, de: <http://www.ufrrj.br/emanped/paginas/-conteudo_producoes/docs_24/modelagem.pdf $>$.

Ministério da Educação (MEC). (1998). Parâmetros Curriculares Nacionais (PCN) Brasília: Ministério da Educação- Retirado em 21 de setembro, 2019, de: <http://portal.mec.gov.br/seb/arquivos/pdf/matematica.pdf>.

Ministério da Educação (MEC). (2017). Base Nacional Comum Curricular: Educação Infantil e Ensino Fundamental. Brasília: MEC/Secretaria de Educação Básica. Retirado em 21 de setembro, 2019, de: 〈http://basenacionalcomum.mec.gov.br/\#/site/inicio〉.

Campos, C. R., Wodewotzki, M. L., Lorenzetti, \& Jacobini, O. R. (2013). Educação Estatística: teoria e prática em ambientes de modelagem matemática. $2^{a}$ ed., 144p. São Paulo: Ed. Autêntica.

Fazenda, I. C. A. (2011). Integração e Interdisciplinaridade no Ensino Brasileiro Efetividade ou Ideologia. $6^{\text {a }}$ ed., São Paulo: Loyola.

Flores, M. (2007). Africanos na Santa Casa de Porto Alegre: Óbitos dos escravos sepultados no cemitério da Santa Casa (1850-1885). Centro Histórico Cultural Santa Casa - Porto Alegre: EST.

Lodovici, F. M. M., \& Silveira, N. D. R. (2011). Interdisciplinaridade: desafios na construção do conhecimento gerontológico. Estudos Interdisciplinares sobre o Envelhecimento. Porto Alegre, 16(2), 291-306.

Lopes, C. E., \& Carvalho, C. (2009). Literacia Estatística na educação básica. Escrituras e Leituras na Educação Matemática. $1^{\text {a }}$ Reimp. Belo Horizonte: Autêntica.

Lopes, C. E. (2010) A educação estatística no currículo de matemática: um ensaio teórico. Anais da $33^{a}$ Reunião da ANPED (pp. 1-15). Retirado em 06 de outubro, 2017, de: 
DOI: 10.20396/zet.v28i0.8656749

<http://33reuniao.anped.org.br/33encontro/app/webroot/files/file/Trabalhos\%20em\%20P DF/GT19-6836--Int.pdf >

Santos Filho, L. (1947). História da Medicina no Brasil: (do século XVI ao século XIX). São Paulo: Ed. Brasiliense. 